\title{
International
}

\section{International Programs at the 2019 Annual Meeting}

\section{RESEARCH DEVELOPMENT GROUPS}

All attendees of the 2019APSA Annual Meeting in Washington, DC are invited to join one of two Research Development Groups short courses featuring research undertaken by early-career African and Arab scholars. Each short course will feature panel sessions with intense discussion and feedback on each paper. Discussion will be moderated by faculty from the US, with a goal of identifying key areas for improvement in pursuit of publication in peer-reviewed journals. The courses are open to enrollment from any APSA member interested in engaging with these discussions and networking with scholars from the Arab Middle East and North Africa.

\section{MENA Workshops}

he first workshop of the 2019 MENA Workshops entitled "Women and Politics: MENA Experiences" took place in Abu Dhabi, UAE from June 9-13, 2019, in partnership with New York University-Abu Dhabi. The second workshop will be held in Rabat Morocco from October 14-18.

The 2019 workshops are led by Naima Benlarabi (Ibn Tofail University, Morocco), Rachel Brulé (New York University-Abu Dhabi, UAE), Hanane Darhour (Polydisciplinary Faculty of Ouarzazate, Morocco), Liv Tønnessen (Chr. Michelsen Institute, Norway), and Aili Mari Tripp (University of Wisconsin-Madison, USA). Together with selected workshop fellows, these co-leaders aim to strengthen the capacities and resources for theoretical and empirical scholarship on politics and gender within the MENA region. Attendees review the recent literature and focus discussion on three areas of analysis. The first theme examines women's representation in legislatures, local government, the executive, and the judiciary as related to factors such as such gender quotas, decentralization, and institutional change. A second theme looks at legal reform, Islamic jurisprudence, and gender equality as related to women's rights reforms and women's economic empowerment. The third theme looks at women's movements and political change as related to policy outcomes, public opinion, international influences, and domestic coalition building.

To provide a framework for reflection and investigation, attendees will critically assess the various research designs and methodological choices used to answer these research questions, and their utility in testing hypotheses. The workshop will also include sessions on conducting fieldwork, manuscript preparation and publication, and other professional development topics. Following their participation in the full program, alumni will receive three years' membership to APSA and will be eligible to apply for small research grants. Participation costs during the workshops (including travel, lodging, and materials) are also covered by the organizers.

The 2019 program is part of a multi-year effort to support political science research among early-career scholars in the Arab Middle East and North Africa and strengthen research networks linking Arab scholars with their colleagues overseas. Previous workshops have been organized in cooperation with the American University in Cairo, the American Center of Oriental Research (ACOR) in Amman, the Center for Maghreb Studies in Tunis (CEMAT), Lebanese American University, Qatar University's Social and Economic Survey Research Institute, and the American University of Beirut's Asfari Institute for Civil Society and Citizenship, among others.

The workshop is intended for citizens of Arab MENA countries who are currently enrolled in a PhD program or completing a post-doctoral fellowship. Non-citizens of Arab MENA countries who are currently based at universities or research institutes in the Arab MENA region are also considered. The program is open to scholars in political science and other social science disciplines undertaking research related to the workshop theme. Interested scholars applied with a manuscript or research project in progress which they shared at the first workshop, improved over the interim period, and will present formally during the second workshop. Professional fluency in English is required. 


\section{Asia Workshop}

he workshop entitled "Dynamics of Political Institutions in Asia" was held from June 23-29, 2019 in partnership with Universiti Sains Malaysia in Penang, Malaysia. Leading the workshop was William Hurst (Northwestern University, USA), Soo Yeon Kim (National University of Singapore), Benny Teh Cheng Guan (Universiti Sains Malaysia), and Meredith Weiss (State University of New York at Albany, USA). The organizers covered the participation costs (including airfare, lodging, and materials) for the participants. The workshop is part of a multi-year effort to support political science research among early-career scholars in East and Southeast Asia, and to strengthen research networks linking Asian scholars with their colleagues overseas.

This workshop explored dynamics of domestic and regional political institutions across Asia. The attendees adopted a broad interpretation of formal political institutions, including (but not limited to) government agencies, legislative and judicial bodies, political parties and organizations, electoral rules and systems, constitutions, international treaties and related agreements, regional associations, and supranational or international organizations. Participants explored core questions and theories of political institutions as well as implications of these theories for political representation, interest intermediation, governance, political liberalization, and regional integration. Employing diverse theoretical frameworks and case studies, the workshop examined the following four themes: Institutions and Political Processes, Liberalization, Democratization, and Authoritarian Resilience, Institutional Innovation, Public Goods, and Governance, and Institutional Approaches to Cooperation and Conflict.

To provide a framework for reflection and investigation, attendees critically assessed the various research designs and methodological choices used to analyze questions related to the aforementioned topics. The workshop included sessions on conducting fieldwork, research and publication ethics, manuscript preparation and publication, and other professional development topics. Workshop sessions included guest lectures, small seminar discussions, and presentations of participants' research. Following the workshop, alumni receive two years' membership to APSA and will be eligible to apply for small research grants.

The workshop was intended for PhD students, post-doctoral fellows, and earlycareer scholars (less than five years from having earned the $\mathrm{PhD}$ ) in political science, international relations, and other social science disciplines who are citizens of countries in East and Southeast Asia, especially those who are currently based at universities or research institutes in the region (defined as Brunei, Cambodia, China, Timor-Leste, Indonesia, Japan, Laos, Malaysia, Myanmar, the Philippines, Singapore, South Korea, Taiwan, Thailand, and Vietnam). Applicants from countries outside the region were also welcomed. Interested scholars applied with a manuscript or research project in progress that they then presented at the workshop. The working language of the workshop was English. 